\title{
Climate and human forcing of Alpine river flow
}

\author{
S.N. Lane, M. Bakker, D. Balin, B. Lovis \& B. Regamey \\ Institute of Earth Surface Dynamics, Université de Lausanne, Switzerland
}

Reproduced from:

Anton J. Schleiss, Giovanni de Cesare, Mario J. Franca and Michael Pfister (eds) RiverFlow2014, 2014.

\begin{abstract}
River flow in Alpine environments is likely to be highly sensitive to climate change because of the effects of warming upon snow and ice, and hence the intra-annual distribution of river runoff. It is also likely to be influenced strongly by human impacts both upon hydrology (e.g. flow abstraction) and river regulation. This paper compares the river flow and sediment flux of two Alpine drainage basins over the last 5 to 7 decades, one that is largely unimpacted by human activities, one strongly impacted by flow abstraction for hydroelectricity. The analysis shows that both river flow and sediment transport capacity are strongly dependent upon the effects of temperature and precipitation availability upon snow accumulation. As the latter tends to increase annual maximum flows, and given the non-linear form of most sediment transport laws, current warming trends may lead to increased sedimentation in Alpine rivers. However, extension to a system impacted upon by flow abstraction reveals the dominant effect that human activity can have upon river sedimentation but also how human response to sediment management has co-evolved with climate forcing to make disentangling the two very difficult.
\end{abstract}

\section{INTRODUCTION}

Alpine environments are likely to be some of the most sensitive to climate forcing, mainly because they contain substantial snow and ice. As climate warms, potentially small changes in temperature can lead to widespread system change at certain altitudes, in terms of both hydrology and sediment flux, and in turn upon river flow and sediment transport. However, Alpine river basins are also often substantially modified by human activity. Few studies address the linkages between climate forcing and river response at the scale of decades, and how such linkages are impacted upon by human activities. Thus, the aim of this paper is to show how decadal-scale climate forcing of river flow may have substantial impacts upon not only river flow, but also sediment flux, in ways that may be detected in river response, for two case-studies in the Swiss Alps.

\section{CLIMATE FORCING OF ALPINE RIVER FLOW}

\subsection{Background and approach}

The forcing of river flow by climate variability is well established in a range of environments. In an Alpine setting, snow is a critical variable, effectively storing precipitation during the winter. Thus, a climate link arises due to the effects of both precipitation and temperature on snow accumulation. The total snow stock accumulating during winter can be reduced in warmer years due to two processes (Scherrer and Appenzeller, 2006): (1) a smaller pro- portion of precipitation that falls as snow; and (2) greater ablation, through a greater probability of rain-on-snow events, as well as more snow melt at higher altitudes earlier in the season. Recent declines in: snow water equivalent; spring snow cover; and/or the thickness of spring snow cover; have been extensively reported, including in the western (e.g. Hamlet et al., 2005) and eastern USA (e.g. Burns et al., 2007) and in the European Alps (e.g. Serquet et al., 2011), linked to warming trends (e.g. Hamlet et al., 2005, Mote, 2006). This trend has been most rapid since the mid 1980s (e.g. Marty, 2008) with evidence of progressively earlier onset of spring snow melt (e.g. Jasper et al., 2004, Birsan et al., 2005, Hodgkins and Dudley, 2006, Horton et al., 2006, Bavay et al., 2009, Fritze and Stewart, 2011). Such changes may impact flow extremes: the probability of low summer flows goes up and the magnitude of annual maximum flows may reduce, because the snow stock is commonly reduced in the late spring and early summer when the probability of warmer rain on snow events is rising, events which can rapidly liberate runoff.

Two important research objectives remain. The first is to look at flow extremes rather than seasonal or monthly runoff. The second is to recognize that most measured flow time series in the Alps contain a complex mixture of climatic and human forcing, often difficult to unravel. Finding basins where climate forcing can be studied in isolation of human impacts is hard because such basins are rarely gauged. Here, we focus upon application of historical climate data to a hydrological model to quantify historical chang- 
es in runoff, 1940 to 2010 , and their implications for sediment transport capacity for an Alpine basin relatively devoid of human impacts, the Avançon basin $\left(78.4 \mathrm{~km}^{2}\right)$, located in the western Swiss Alps. Basin altitude varies from $3051 \mathrm{~m}$ to $420 \mathrm{~m}$. Climate is humid, temperate with strong Atlantic influence but also strong altitudinal gradients in temperature (between 3.5 and $7{ }^{\circ} \mathrm{C}$ ) and precipitation (between 1000 and $3000 \mathrm{~mm}$ ). Much annual precipitation can fall as snow, especially at altitude, making the basin extremely sensitive to climatic variability, temperature and precipitation. The hydrological regime is partly influenced by small glaciers (1.7\% of the surface), found in the upper parts of the basin. Land use is dominated by forest and meadow. Grazing of some of the meadow areas is restricted by convention.

\subsection{Historical flow reconstruction}

Historical flow reconstruction focuses upon application of the deterministic Water balance Simulation Model (WaSiM-ETH, Schulla, 2012): (1) we calibrated the model for a period when as many of the model's data needs could be met through direct measurement; and (2) we used a series of secondary models to provide the input data needed to apply the model over the period 1940 to 2010. WaSim-ETH is described in full in Schulla (2012) and only a very brief summary is provided here. The model simulates evapotranspiration, snow accumulation, snowmelt, glacier and firn melt, infiltration and generation of surface and subsurface flow. Spatial variability is represented in terms of orthogonal grid cells discretized over the basin surface, described using a digital elevation model, land use and soil type. Precipitation and temperature are the basic meteorological data required for the model, which can be locally supplemented by additional meteorological data where available, such as global radiation, relative sunshine duration, wind velocity, relative humidity and vapor pressure.

Hydrological process representation is based upon a combination of the Green and Ampt (1911) infiltration excess treatment (Peschke, 1987) and the TOPMODEL approach for the simulation of runoff generation from infiltration excess and saturated areas. WaSiM-ETH generates surface runoff when the unsaturated zone is filled and routes it to the streams using a kinematic wave approach (Schulla, 2012). To represent snow, glacier and permafrost effects the model: (1) treats accumulation using a temperature threshold; (2) represents snow melt using a day degree method; and ( 3 has a glacier model to describe the melt of ice, firn and snow on glaciers, using a temperature index method.

To run the model for the period 1940 to 2011, we needed: (1) daily time series of meteorological data for the full time period; (2) to downscale these data from a daily to hourly time steps; and (3) to dis- aggregate the data spatially across the model domain. This was undertaken differently for: (1) temperature, relative humidity, wind speed and solar radiation; and (2) precipitation.

For the group 1 parameters, the daily downscaling was achieved using ClimGen (Stöckle et al., 1999). ClimGen generates synthetic daily data either from data series that are too short or from monthly means. We had hourly data or Aigle, a station close to the study catchment, for the period 1981 to 2011, which we used to train ClimGen and then applied the parameterized model to generate daily mean, minimum and maximum values for these parameters for the whole period 1940 to 2011 . For the disaggregation of these daily data to hourly data, for all parameters except precipitation, we followed Debele et al. (2007). For rainfall disaggregation we used the MUDRAIN method of Koutsoyiannis et al. (2003).

Model calibration focused on the hydrological year 2010 to 2011 . One at a time sensitivity analysis was used to identify sensitive parameters and then the automated PEST procedure was used to identify plausible parameter values. We compared the calibrated model predictions with measured discharge for the period from January 2007 to December 2009 to assess parameter transferability.

Figure 1 shows mean annual temperature, mean annual total precipitation and the maximum and minimum annual accumulated snow, by hydrological year, with a 12 year running mean. The data confirm that the period is an interesting one in which to study climate forcing because there are distinct periods of cooler/warmer and wetter/drier climates, albeit with substantial natural variability. There is a period into the mid 1970s of relatively low levels of annual snow accumulation, a period from the mid 1970s until the early 1980s where snow accumulation is systematically higher, a rapid decline into the early 1990s and a more gradual decline after that.

It is possible to see the effects of these changes in example annual flow percentiles (Fig. 2). There is clear forcing of river flow by accumulated snow, with the period of greater than average snow accumulation (Fig. 1c) also associated with larger high flows and low flows. The latter reflect the effects of snow accumulation on sustaining summer low flows. The greater magnitude high flows reflect the effects of significant snow accumulation on the probability of a warm rain on snow event, which is greater in the summer months. Indeed, the association between the annual maximum flow magnitude and the annual maximum accumulated snow depth is extremely clear (Fig. 3).

\subsection{Implications for sediment transport capacity}

To assess the implication of these changes in river flow for sediment transport capacity, we have de- 
veloped a simple model SEDALP. We use a mathematical modeling approach that has been extensively evaluated for instrumented Swiss catchments (Nitsche et al., 2011) and are comparable with the Avançon basin.
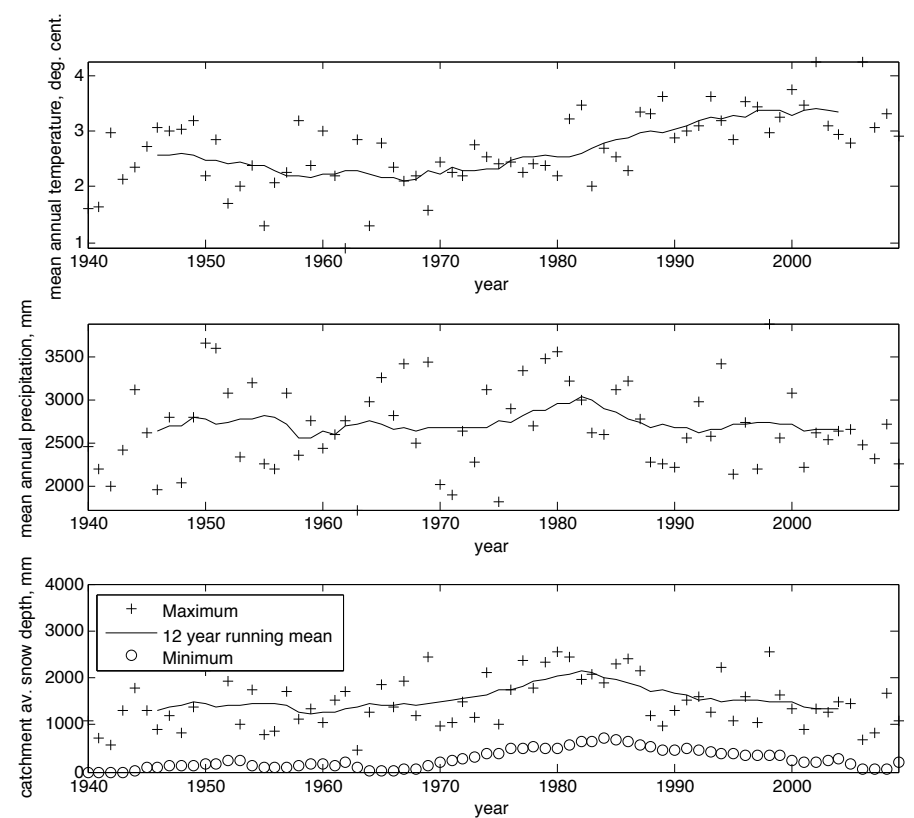

Figure 1. Mean annual temperature (1a), mean annual total precipitation ( $1 \mathrm{~b})$ and the maximum and minimum annual accumulated snow (1c), by hydrological year, with a 12 year running mean.
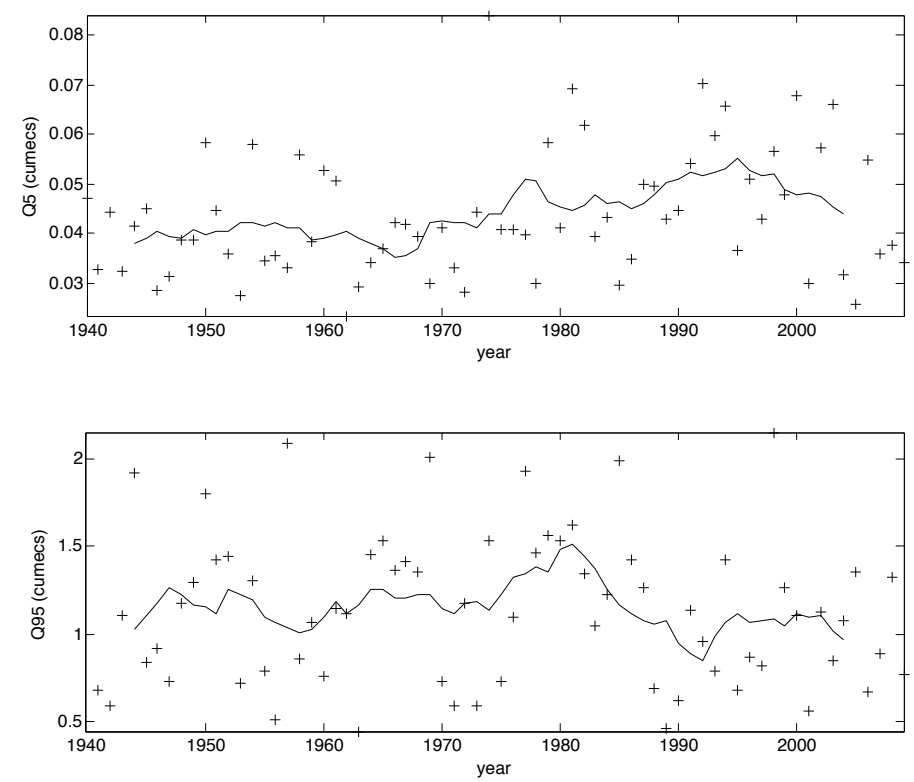

Figure $2.5^{\text {th }}$ and $95^{\text {th }}$ percentiles of river flow.

Many bedload transport equations for rivers have been based upon flume experiments and, to a lesser extent, instrumented river catchments with relatively low bed slopes and relative roughness (Nitsche et al., 2011). They tend to under-estimate energy losses associated with macroform roughness and hence over-estimate bedload flux. Nitsche et al. showed that over prediction of bedload flux could be substantially reduced by inclusion of an improved representation of flow resistance. However, they also showed that a simpler approach (Rickenmann and Recking, 2011) that included additional energy losses linked to roughness elements, but where no information on the detailed spatial organization of roughness elements is available, produced the best overall results. They attributed the success of this simpler model to either: (1) inadequacies in the physical representation of roughness elements in more complex treatments; and/or (2) the difficulties of identifying and measuring those elements in field data. Given the success of the Rickenmann and Recking (2011) approach in the evaluation of models by Nitsche et al. (2011), and the similarity of the Avançon to those streams considered, the Rickenmann and Recking (2011) model is used here for the calculation of sediment transport capacity.

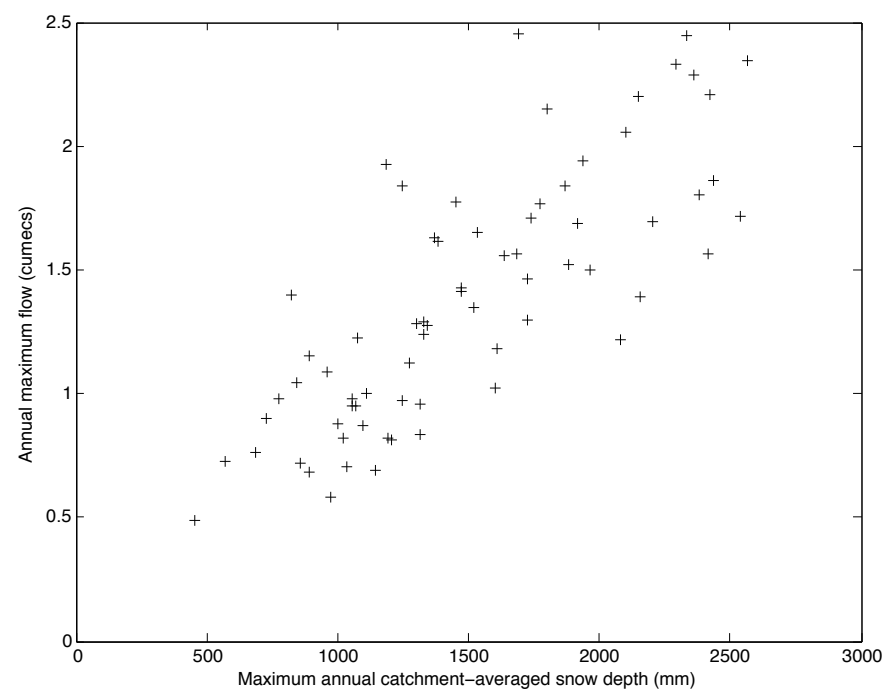

Figure 3. Annual maximum flow magnitude plotted against annual maximum accumulated snow depth.

This application requires specification of two models: (1) flow resistance; and (2) sediment transport capacity. For flow resistance, following Rickenmann and Recking (2011), the slope $(S)$ of the energy line is partitioned into: that lost on overcoming flow resistance; and that available for sediment transport $\left(S_{0}\right)$, associated with grain friction; after Meyer-Peter and Müller (1948):

$$
S_{0}=S\left[\left(\frac{n_{0}}{n_{\text {tot }}}\right)^{0.5}\right]^{e}
$$

where: $n_{\text {tot }}$ is the Manning parameter, for total roughness; $n_{0}$ is that associated with grain friction and $e$ is set at 1.5 following Nitsche et al. (2011). Following Rickenmann and Recking (2011), the Variable Power Equation (VPE) of Ferguson (2007) accounts for the depth dependence of roughness.

First, we write expressions for velocity $\left(v_{t o t}\right)$, which includes all energy losses, and that velocity associated with the grain scale $\left(v_{0}\right)$ only in terms of a friction factor $(f)$ (and where by definition $v_{0}>v_{t o t}$ ): 


$$
\begin{gathered}
\sqrt{8 / f_{\text {tot }}}=v_{\text {tot }} /(g R S)^{0.5} \\
\sqrt{8 / f_{0}}=v_{0} /(g R S)^{0.5}=6.5\left(R / D_{84}\right)^{0.167}
\end{gathered}
$$

[2 and 3]

where: $g$ is the gravity constant; $R$ is the hydraulic radius, and $D_{84}$ is the 84th percentile of grain-size. On this basis:

$$
\sqrt{f_{0} / f_{t o t}}=v_{t o t} / v_{0}
$$

and in combination with [1]:

$$
S_{0}=S\left[\left(\frac{v_{t o t}}{v_{0}}\right)\right]^{e}
$$

The VPE provides a means of estimating the crosssection averaged flow velocity mirroring traditional flow resistance equations but allowing for the effects of changing flow depth upon flow resistance:

$$
v_{t o t}=\frac{6.5(g R S)^{0.5} 2.5\left(R / D_{84}\right)}{\left[6.5^{2}+2.5^{2}\left(R / D_{84}\right)^{1.67}\right]}
$$

The grain-scale velocity is then estimated from a Manning-Strickler type equation (Nitsche et al., 2011):

$$
v_{0}=6.5(g R S)^{0.5}\left(R / D_{84}\right)^{0.167}
$$

Application of [6] and [7] to [5] allowed calculation of a reduced slope, taken as that to be effective for the transport of sediment and which is in turn applied to a sediment transport equation.

After Nitsche et al. (2011), sediment transport is calculated using the unit discharge approach of Rickenmann (2001). The sediment transport rate (per unit width, $q_{b}$ ) is defined by:

$$
q_{b}=1.5\left(q-q_{c}\right) S_{0}^{1.5}
$$

where: $q$ is the discharge per unit width; and $q_{c}$ the critical discharge per unit width. The critical discharge per unit width is defined by:

$$
q_{c}=0.065(s-1)^{1.67} g^{0.5} D_{50}^{1.5} S_{0}^{-1.12}
$$

where $s$ is the density of sediment. The formulation in [9] is a relatively simple threshold-based sediment entrainment formula, which does not account for processes that have been shown to be important in flume experiments (e.g. the role of a sand fraction in reducing the critical discharge necessary for sediment entrainment; Wilcock and Crowe, 2003). However, this was found by Nitsche et al. (2011) to be effective in representing sediment transport provided the slope was reduced to correct for form roughness effects as per [1]. There are no field measurements of sediment transport in the Avançon system and so this approach, validated for a large number of instrumented Swiss catchments (Nitsche et al., 2011), was adopted.

A straightforward application of SEDALP is complicated as the Avançon is multi-thread in places including in the reach considered here. To apply the model to the section we consider in this paper, the river was treated as a series of panels, as defined by the river cross-section morphology. For any individual river section, a series of water levels were considered in increments of $0.5 \mathrm{~mm}$ above the minimum elevation in that section. For each water level, and under the (severe) assumption that there was no difference in water level between branches of the section, the number of occupied branches was calculated. The water level and cross-section morphology was then used to calculate the hydraulic radius for each branch, and the Ferguson VPE ([6]) was applied to calculate the velocity, using also the local downstream river slope and measured grain-size data. Estimated velocity was then combined with the width and the depth for each branch to calculate branch discharge. Discharges were then summed for all branches to give the discharge estimated for that water level. By undertaking this for a large number of water levels, it was possible to create a look up table that, for a given discharge, allowed the estimation of the number of branches occupied by water, and the velocity, width and depth of each branch. As water levels rose, two branches could become a single branch. In this case, to avoid sudden jumps in the hydraulic geometry of the river, the two branches were kept as separate panels, mirroring what happens in one-dimensional models of flood inundation.

For each discharge predicted by the hydrological model, the closest discharge in the look up table was identified, and hence the number of branches, and the velocity, depth and width of each branch. For each branch, the reduced slope was calculated as per [1], applied to [5] and then used with the branch discharge. In the final stage, the bedload transport per unit width for each branch is converted to a total bedload transport for each branch and summed for all branches.

Here, we show the results for one section, representative of the braided reach of the river. It is also contained within a reach where there has been active deposition over the last 10 years. Figure 4 shows the cumulative annual deviation from the average annual sediment transport rate: values greater than zero 
show periods with greater than average sediment transport. Also shown is the catchment averaged minimum snow depth in $\mathrm{mm}$. Given the link between the characteristics of snow accumulation and annual maximum flows, and the use of a non-linear sediment transport law ([8]), it is not surprising that there is a clear association between snow accumulation and sediment transport, albeit with a small lag showing that sediment transport is commonly greater after elevated periods of snow fall, in this case as indicated by minimum snow depths, that is periods of release of accumulated snow to runoff. The period until the 1970s has markedly less than average sediment transport rates. These rise from the mid 1970s to the mid $1980 \mathrm{~s}$, and then decline thereafter back until their long-term average by 2010 .

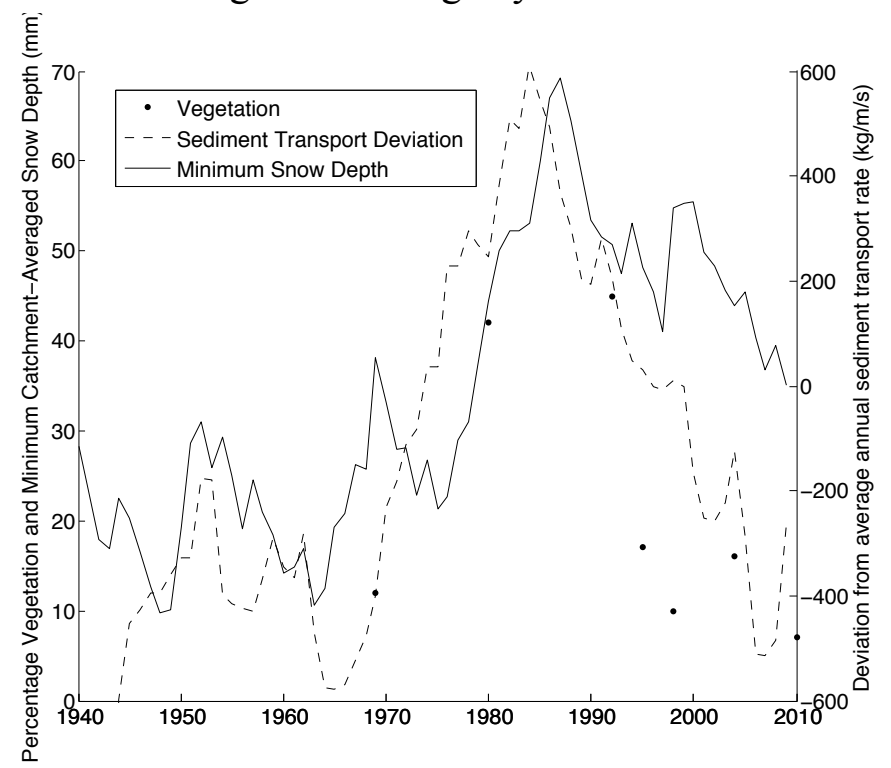

Figure 4. Cumulative annual deviation from the average annual sediment transport capacity, minimum snow depth and the percentage of the studied river plain that is vegetated.

We have aerial imagery for the section of river used for SEDALP. This has been orthorectified and analyzed to assess if there is a geomorphic response during this period. We focus upon a $1.5 \mathrm{~km}$ long reach with approximately constant slope and calculate the percentage of vegetation within a fixed width within this area. Figure 4 superimposes these data and shows how during the colder and snowier period, associated with greater sediment transport capacity, there was also a greater degree of vegetation development on the terraces that formed following riverbed incision. As sediment transport capacity falls from the late 1980s onwards, the percentage vegetation falls rapidly as the amount of sediment cover rises, with sedimentation occurring on the terraces formed during the incision. Two points follow. First, there appears to be a climate forcing of geomorphic response through the effects of colder periods on sediment transport capacity arising from snow stock effects. Second, sediment transport capacity is not necessarily the same as actual sediment transport rates, as the latter will be influenced strongly by sediment supply. In this catchment, the warming seen since the 1980s may equally have led to a greater sediment flux to the valley bottom, associated with melting permafrost. But, if snow is also responsible for this transfer, it is equally possible that less snow accumulation has slowed this flux.

\subsection{Synthesis}

This study of historical Alpine river flow and its effect upon sediment transport capacity and river dynamics suggests that temperature and precipitation and their combined effect upon snow accumulation may be critical in understanding how basins respond to changing climate. A clear association between annual maximum flow and snow accumulation emphasizes that in Alpine catchments, the probability of high river flow events may actually be reduced and not increased under a warming climate, if that climate reduces snow accumulation. This trend may also lead to reduced sediment transport capacity and so to progressive sediment deposition and resulting in serious sediment management problems.

\section{HUMAN FORCING OF ALPINE RIVER FLOW}

\subsection{Background and approach}

The above focus was on a catchment that had minimal human impact. As such, it allowed a form of experimental control, in which direct human impacts are kept relatively constant, to show how climatic variability forces river flow, and perhaps also sediment transport. However, the vast majority of Alpine drainage basins are actually exploited for a range of reasons: hydroelectric power production; gravel and sand extraction; tourism etc. These can have profound impacts, not only upon river flow, but also sediment flux, river channel morphology and ecosystems. Whilst the hydrological and geomorphological effects of dams upon the rivers downstream have been studied for may years, there are fewer studies of a type of system that is extremely common in Alpine systems where flow regulation does not involve accumulation behind a dam. Rather, water abstraction and transfer takes place through tunnels, either: (1) to a dam in another drainage basin; or (2) downstream within the same drainage basin, but where the water is kept at altitude to create a greater hydraulic head for hydroelectric power production. Figure 5 shows a schematic of this kind of system in the Southern Swiss Alps. Water, primarily from snow or glacier melt, is taken off and transferred (sometimes after pumping to higher altitudes) through a network of tunnels to a reservoir in an adjacent valley. Then water is stocked and released ac- 
cording to energy demands, which substantially alters the discharge regime of the main river both upstream and downstream of the HEP generation plant. Alpine catchments commonly have very high sediment production rates (e.g. Harbor and Warburton, 1993), a result of both glacial and paraglacial processes, such that sediment delivery rates to the tributary headwaters can be very high. This may lead to significant sediment accumulations in the intakes, necessitating periodic evacuation of sediments to the downstream river. Thus, sediment tends to remain in the system whilst the capacity to transport it is withdrawn from the system and used for hydropower generation. There are surprisingly few studies of this kind of human forcing at the scale of river basins especially over the long-term, despite flow abstraction and transfer being a dominant hydroelectric power approach in the European Alps. Here, we aim to quantify the effects of this kind of management upon the river system for a major flow abstraction scheme.

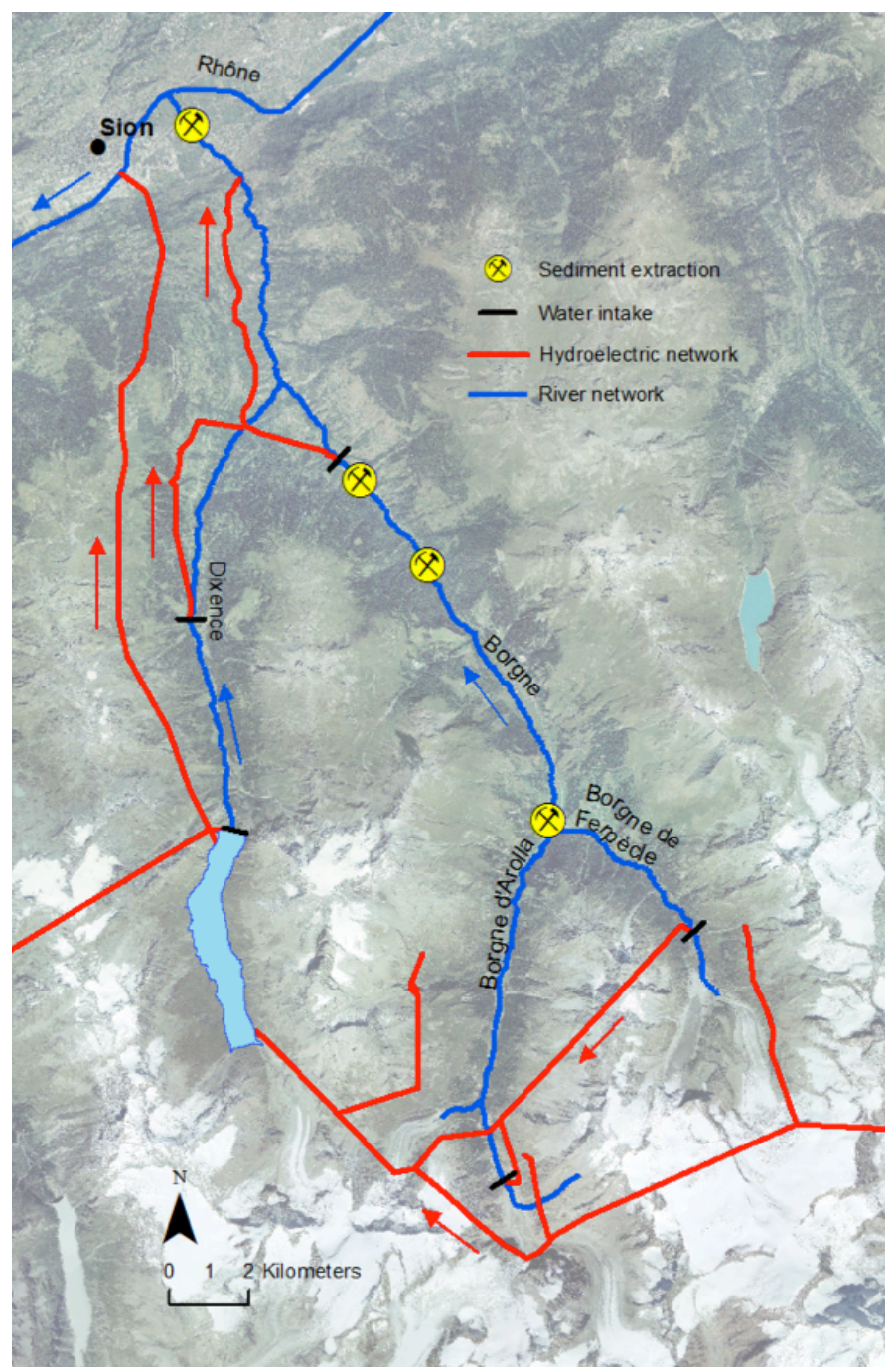

Figure 5. The western part of the Grande Dixence SA hydroelectric power system. Base image SwissTopo $C$.

\subsection{The Grande Dixence scheme}

The Grande Dixence scheme in Southwest Switzerland (Fig. 5) has its origins in the 1920s, initially as a conventional single valley-dammed system. In the 1950 s, to create greater hydroelectric power production, the storage volume was increased and supply from other valleys was developed. The result was: (1) the Dixence dam, which came into service in 1961 , at an altitude of 2'385 m with a dam height of $285 \mathrm{~m}$ and able to stock 400 billion cubic meters of water; and (2) a $100 \mathrm{~km}$ network of tunnels, including a $24 \mathrm{~km}$ major tunnel at 2'400 m altitude, capturing water from 35 glaciers, through 75 intakes and with an additional 4 pumping stations to pump water from lower basins to the 2' $400 \mathrm{~m}$ tunnel.

Herein, we focus upon the Borgne d'Arolla, a left bank tributary of the River Rhône that lies within the Grande Dixence system, where we have quantified how human forcing of river flow impacts the river system over daily, seasonal and decadal timescale. Here we focus upon the decadal timescale.

\subsection{Decadal-scale response}

To quantify the decadal scale response of the river system we used archival digital photogrammetry (Lane et al., 2010). Historical imagery was available from 1959, just before the major phase of development of water intake, through until 2010. The quality of data that can be obtained from such imagery is primarily controlled by image scale but this relationship is well established such that given a set of historical images we can determine a priori the quality of the data that will be obtained. Ground control is needed, using points that are genuinely fixed throughout the period of study, and aided by the fact that there is some human habitation in the valley, which we used for this purpose.

Figure 6 shows photogrammetrically-estimated erosion and deposition within the Borgne between 1959 and 2010. There are three zones of deposition, each in areas of reduced valley slope and separated by river gorges. The most upstream area of Figure 6 (reach A in Fig. 7) has substantial deposition, greater than $3 \mathrm{~m}$ in places. The middle area (reach B in Fig. 7) has substantial deposition, but also some zones of net erosion, reflecting local river engineering works designed to straighten the river and reduce sediment accumulation. The downstream area (reaches $\mathrm{C}$ and $\mathrm{D}$ in Fig. 7) has substantial deposition, laterally greater in extent because of greater accommodation space. Reach D is also influenced by supply of sediment from a right bank alluvial fan, reducing local valley slope and encouraging deposition.

Imagery in Figure 7 shows that for the most upstream reach (A) where there was the largest impact of construction works, active river channel narrowing occurred to 1983, linked to post-construction recovery (see Gurnell, 1983). But, from 1983 to 1994, active channel width increases, after which it becomes more stable. Reach B shows a similar trend until artificial straightening in the early 1990s. By 
contrast, Reach C also narrows to 1983 , but widens most rapidly from 1988 through to 1994 . Reach D shows some vegetation development to 1983 , followed by sedimentation, more rapid from 1988 to 1994. By 1994, there appears to have been an avulsion towards the right, which then re-vegetates until 2010 when it re-occurs.

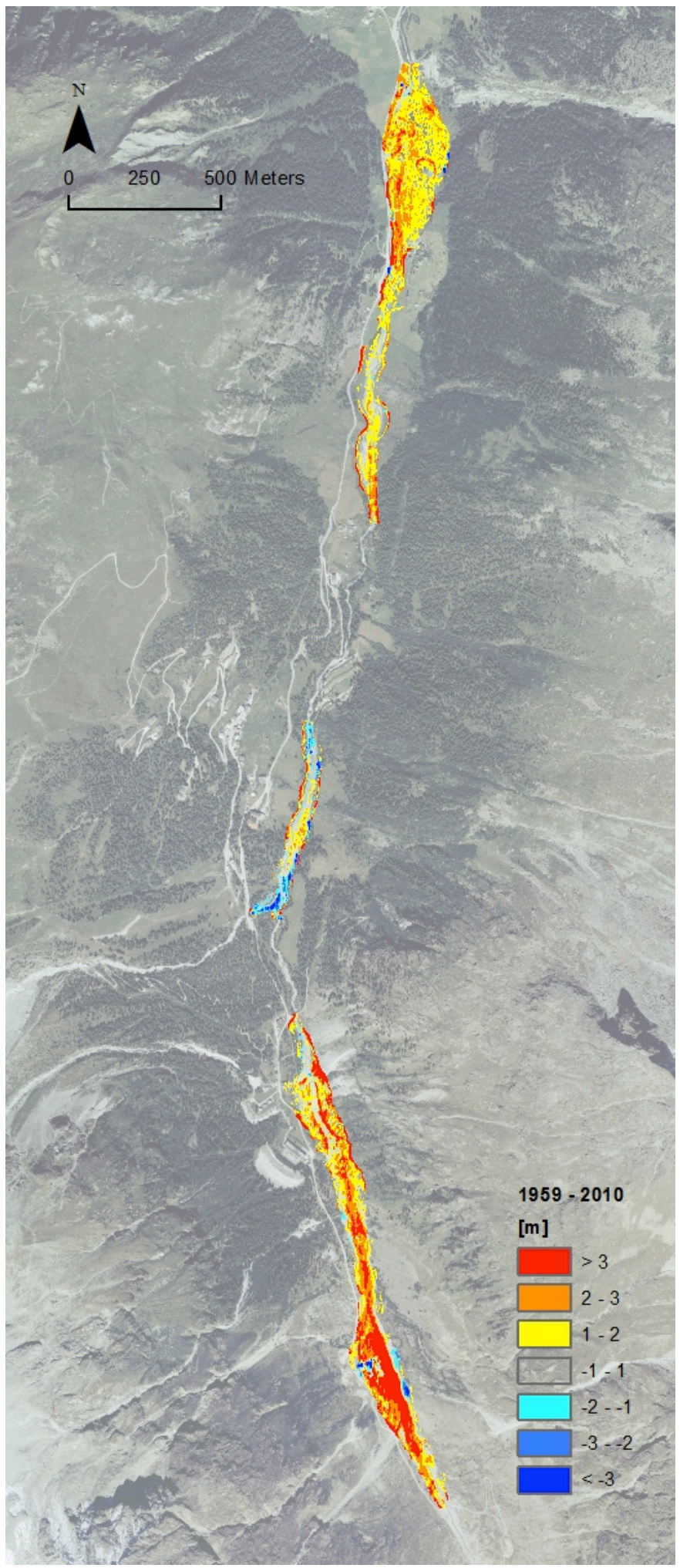

Figure 6. Elevation changes between 1959 and 2009. River flow is from bottom to top.

\subsection{Climate forcing}

Figures 6 and 7 suggest substantial changes in the evolution of the Borgne d'Arolla. It is tempting to link these to flow abstraction and the reduction in sediment transport capacity. Doing so is dangerous, not least due to the evidence in Section 2 which suggests that over the timescale shown in Figure 7 there has also been considerable climate forcing of hydrological response and so sedimentation. As these are regulated systems, we are fortunate that they are also extremely well documented, with reliable discharges measured at each intake. Application to the SEDALP model allows us to calculate the annual sediment transport capacity upstream of the flow intakes.

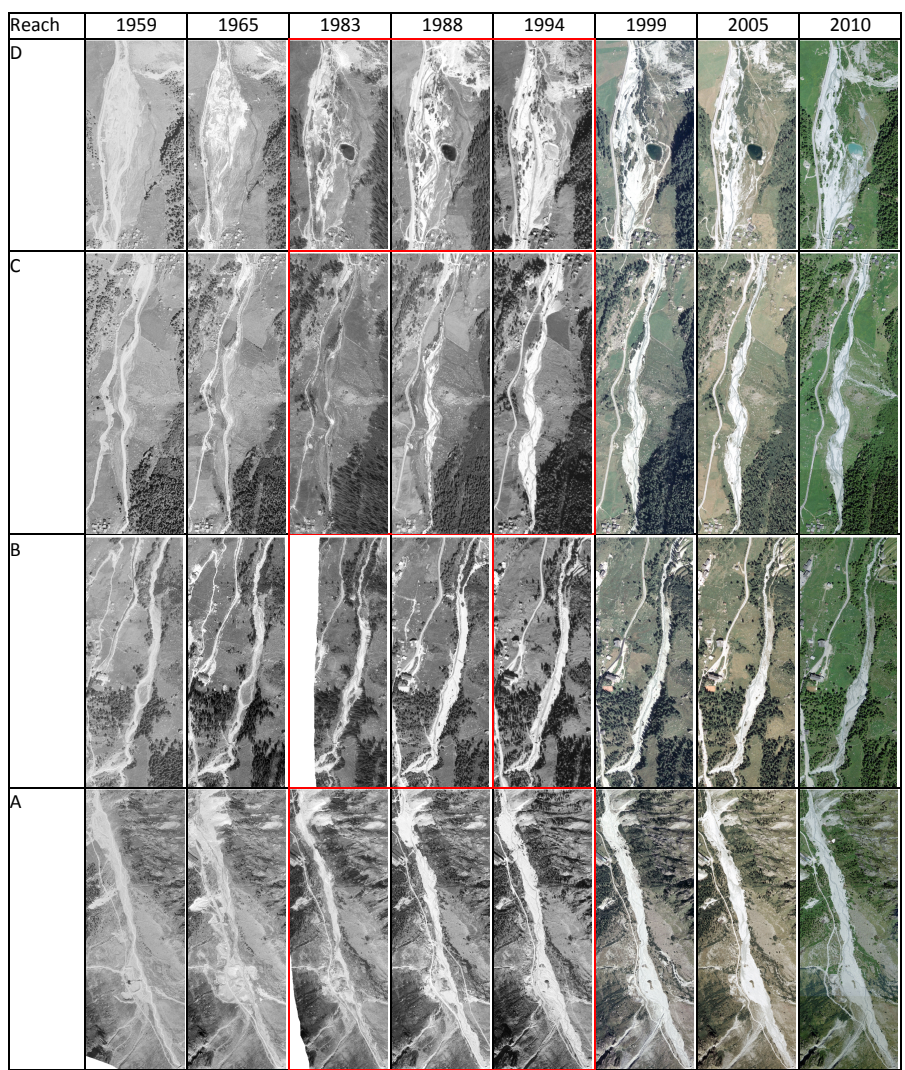

Figure 7. Orthorectified aerial images for four reaches of the Borgne d'Arolla from before the HEP development (1959) to 2010 , orthorectified from aerial imagery (SwissTopo ${ }^{\circledR}$ ).

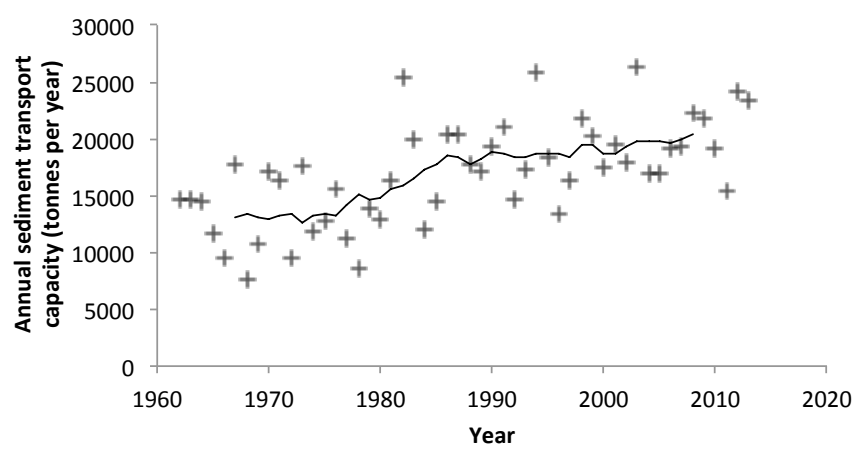

Figure 8. Annual sediment transport capacity, Haut Glacier d'Arolla (upstream of the intake) with a 12 year running mean.

Figure 8 shows some similarity but also some differences as compared with the results from Section 2: 
modeled annual sediment transport capacity rises from the late 1970 s to the late 1980 s, remains fairly stable (but variable) to the early 2000s and then appears to be rising again. This is different to the Avançon basin (Fig. 4), reflecting the importance of the glaciated part of the Borgne basin, and progressive loss of ice as mean annual temperature continues to rise. Figure 7 suggests that the 1983-1994 sedimentation increase could also be caused by increases in upstream sediment transport capacity and delivery of more sediment to the intakes, so increasing purge frequency. This conclusion is tentative for two reasons. Significant glacier recession during this period could have resulted in a greater sediment delivery. Removal of sediment transport capacity downstream of intakes will substantially slow the duration of sediment transport, making it unlikely that the 1983 to 1988 morphological response should occur simultaneously with the sediment transport capacity increase but rather reflect progressive sediment translation in the downstream direction.

\subsection{Synthesis}

As compared with a basin with low human impact (Section 2), it is clear that human forcing can substantially impact a river system. However, disentangling human forcing from other forcing such as local relief (which determines local valley slope and available accommodation space) or climate is difficult. Further work is needed to quantify how climate forcing impacts on sediment transport capacity and sediment delivery, and how purging has changed the rate at which such climate signals propagate through the river to create downstream impacts.

\section{CO-EVOLUTION OF CLIMATE AND HUMAN IMPACTS ON ALPINE RIVER FLOW}

Both case studies shown here suggest that Alpine river flow is likely to have been to marked stationarity over the last decades, with evidence that this can be traced into river response. Clearly, further work is required to understand the time scales and rates of these processes in a way that can integrate the diverse ways in which climate and humans are impacting upon Alpine environments. However, one more fundamental challenge relates to the way in which climate and human forcing co-evolve in Alpine environments, making it difficult to separate out climate and human forcing. Here are two examples. In response to rising sediment transport capacity during the 1980s, the Haut Glacier d'Arolla intake had to be redesigned in the early 1990 s to have greater capacity. It led to less frequent purging, but it also reduces the residual flow released during purges. The Borgne d'Arolla, as shown in Reach B, has been straightened to increase local sediment flux capacity, something that in leading to local erosion may have impacted upon downstream sediment delivery. Having worked in the Borgne since 1989, it is possible to see a suite of other examples that reflect the progressive interaction between humans and their environment centered on the management of changing river flow. Not only will separating climate and human impacts upon river flow be difficult, it may not be entirely meaningful.

\section{ACKNOWLEDGEMENTS}

This work was supported by the Swiss Research Council (SNF), Fondation Herbette, and the University of Lausanne. SwissTopo ${ }^{\circledR}$ supplied aerial imagery. Hydroexploitation and Grande Dixence SA supplied flow data for the Haut Glacier d'Arolla. The Commune d'Evolène and its residents provided additional support in a number of ways.

\section{REFERENCES}

Bavay, M., Lehning, M., Jonas, T. \& Löwe, H. 2009. Simulations of future snow cover and discharge in Alpine headwater catchments. Hydrological Processes, 23, 95-108.

Birsan, M.V., Molnar, P., Burlando, P. \& Pfaundler, M. 2005. Streamflow trends in Switzerland. Journal of Hydrology, 312-29.

Debele, B., Srinivasan, R. \& Parlange, J.Y. 2007. Accuracy evaluation of weather data generation and disaggregation methods at finer timescales. Advances in Water Resources, 30, 1286-300.

Ferguson, R.I. 2007. Flow resistance equations for gravel- and boulder-bed streams. Water Resources Research, 43, W05427.

Fritze, H. \& Stewart, I.T. 2011. Shifts in Western North American Snowmelt Runoff Regimes for the Recent Warm Decades. Journal of Hydrometeorology, 12, 989-1006.

Gurnell, A.M. 1983. Downstream channel adjustments in response to water abstraction for hydroelectric power generation from Alpine glacial meltwater streams. Geographical Journal, 149, 342-54.

Hamlet, A.F., Mote, P.W., Clark, M.P. \& Lettenmaier, D.P. 2005. Effects of temperature and precipitation variability on snowpack trends in the western United States. Journal of Climate, 18, 4545-4561.

Harbor, J. \& Warburton, J. 1993. Relative rates of glacial and nonglacial erosion in alpine environments. Arctic, Antarctic and Alpine Research, 25, 1-7.

Hodgkins, G.A. \& Dudley, R.W. 2006. Changes in the timing of winter-spring streamflows in eastern North America, 1913-2002. Geophysical Research Letters, 33, GL025593.

Horton, P., Schaefli, B., Mezghani, A., Hingray, B. \& Musy, A. 2006. Assessment of climate-change impacts on alpine discharge regimes with climate model uncertainty. Hydrological Processes, 20, 2091-109. 
Jasper, K., Calanca, P., Gyalistras, D., \& Fuhrer, J. 2004. Differential impacts of climate change on the hydrology of two alpine river basins. Climatic Change, 26, 113-129, 2004.

Koutsoyiannis, D., Onof, C. \& Wheater, H.S. 2003. Multivariate rainfall disaggregation at fine timescale. Water Resources Research, 39, 1-18.

Lane, S.N., Widdison, P.E., Thomas, R.E., Ashworth, P.J., Best, J.L., Lunt, I.A., Sambrook Smith, G.H. \& Simpson, C.L. 2010. Quantification of braided river channel change using archival digital image analysis. Earth Surface Processes and Landforms, 35, 971-85.

Marty, C. 2008. Regime shift of snow days in Switzerland. Geophysical Research Letters, 35, L12501.

Meyer-Peter, E., \& Müller, R. 1948. Formulas for bed-load transport. Proc. 2nd IAHR Meeting, Stockholm, 39-64.

Mote P.W., 2006. Climate-driven variability and trends in mountain snowpack in western North America. Journal of Climate, 19, 6209-20.

Nitsche, M., Rickenmann, D., Turowski, J.M., Badoux, A. \& Kirchner, J.W. 2011. Evaluation of bedload transport predictions using flow resistance equations to account for macroroughness in steep mountain streams. Water Resources Research, 47, WR010645.

Peschke G. 1987. Soil moisture and runoff components from a physically founded approach. Acta Hydrophys. 31, 191-205.

Rickenmann, D. 2001. Comparison of bed load transport in torrents and gravel bed streams. Water Resources Research, 37, 3295-3305.

Rickenmann, D \& Recking, A., 2011. Evaluation of flow resistance equations using a large field data base. Water Resources Research, 47, W07538.

Scherrer, S.C. \& Appenzeller, C. 2006. Swiss Alpine snow pack variability: major patterns and links to local climate and large-scale flow. Climate Research, 32, 187-99.

Schulla J. 2012. Model Description WaSiM (Water balance Simulation Model), Zürich, Hydrology Software Consulting.

Serquet G., Marty C., Dulex J.-P. and Rebetez M. 2011. Seasonal trends and temperature dependence of the snowfall/precipitation-day ratio in Switzerland. Geophysical Research Letters, 38, L07703.

Wilcock, P. \& Crowe, J. 2003. Surface-based Transport Model for Mixed-Size Sediment. J. Hydraul. Eng., 129, 120-128. 